\title{
Calculation of bed load based on the measured data of suspended load
}

\author{
Chang-Tai Tsai $\cdot$ Chih-Heng Tsai $\cdot$ \\ Chun-Hung Weng $\cdot$ Jinn-Jong Bair • \\ Ching-Nuo Chen
}

Received: 1 June 2010/Revised: 7 July 2010/Accepted: 31 July 2010/Published online: 12 September 2010

(C) The Author(s) 2010. This article is published with open access at Springerlink.com

\begin{abstract}
This paper proposes a method for establishing both the velocity profile and concentration profile for suspended sediment based on measured data consisting of average velocity and average suspended sediment concentration in the river and the irrigation channel. In addition, a numerical model for computing suspended load and bed load was also developed for computing bed load transport rate when measurable load is available. In this study, bed loads for published laboratory and field sediment data were computed using the presently developed numerical model based on four different bed layer thicknesses. The computed bed loads were found to be in reasonable agreement with the values from Einstein's bed load function when the thickness of the bed layer was taken at $10 \theta d$ or $0.05 D$. The numerical model developed in this study may be used to evaluate the validities of other bed load formulas.
\end{abstract}

Keywords Suspended load $\cdot$ Bed load $\cdot$ Bed-material load $\cdot$ Velocity profile $\cdot$ Concentration profile

C.-T. Tsai $(\bowtie) \cdot$ C.-H. Weng · C.-N. Chen

Department of Hydraulics and Ocean Engineering,

National Cheng-Kung University, No. 1, University Road,

Tainan City 70101, Taiwan

e-mail: jhwong@mail.hyd.ncku.edu.tw

C.-H. Tsai

Department of Resources and Environment, Leader University, No. 188, Section 5, Anjhong Road, Tainan City 70970, Taiwan

J.-J. Bair

Chia-Nan Irrigation Association, No. 25, yu-ai Street,

Tainan City 70041, Taiwan

\section{Introduction}

The sediment load in an irrigation channel is admitted at the channel headworks. A stable channel will convey the required sediment load without undue deposition or scour. Therefore, the stability of both the irrigation channel and the river channel are affected by the sediment transport rate.

Estimation of sediment transport should be based on the comprehension of the mechanism between hydraulic characteristics and sediment characteristics for an irrigation channel or a river channel. Therefore, many studies have developed empirical, half-empirical, and theoretical methodologies to describe the phenomenon of sediment transportation. These methodologies can be separated into two categories based on the necessity of measured data. In the first category, formulations do not require measured data, such as Du Boys, Schoklitsch, Einstein, and Yang formulas, etc.; these formulations utilize the geometric shape of river channels and bed-material to estimate the sediment transport rate. The respective results from these models are usually different because of their different theoretical bases. In addition, some of these models, developed from experiments in laboratories, do not accurately estimate sediment transportation in real-life river channels or canals. In the second category, formulations require measurable load data to estimate suspended load and bed load (e.g., modified Einstein method), or to calculate total sediment transportation (e.g., Colby equation). The previously mentioned measurable load data consists of suspended loads measured by sampling equipment. Therefore, methodologies belonging to the second category only apply to sandy bed-material rivers that have suspended sediment.

No single methodology is currently applicable to every type of river or irrigation channel. Therefore, selecting a 
suitable model requires careful consideration of the theory of the model and the data availability. These data may include channel bed slop, flow velocity, bed composition, and water temperature. Some researchers focus on the velocity profile or the sediment concentration profile for sediment-laden flow by using numerical method or analytical solution (Wang et al. 2001; Jung et al. 2004; Lin and Huang 2008). However, the sediment exchange coefficient is related to the fluid diffusion coefficient, the sediment-laden flow problems cannot be simply resolved with individual study on velocity distribution or on concentration distribution.

It is very rare or very difficult to measure the bed load data in the sand channel. The measured data available are usually measured suspended load data. Therefore, the modified Einstein method was selected for this study because this method can estimate bed load transport rate by measured load data. Moreover, this method can evaluate appropriate bed load formulas and suspended load formulas for calculating sediment transport rate when no measured load data is available. This modified Einstein method applies the bed load curve from Einstein method to calculate bed load transport rate as well as suspended load transport rate. Measured load data allows for the determination of the concentration distribution index of suspended load.

In this study, a numerical model was developed, using measured average suspended sediment concentration and average flow velocity data, to estimate velocity profiles and concentration profiles and calculate suspended load transport rate and bed load transport rate. This numerical model will be used to evaluate the validity of a bed load formula when measurable load and average flow velocity are available.

\section{Methodology}

Figure 1 shows the relationship between suspended sediment concentration $C(y)$ and flow profile $u(y)$ in an open channel. In this figure, $D$ is the depth; $y_{a}$ is the thickness of bed layer; $y$ is the vertical coordinate with respect to the bed surface. The flow condition can affect the sediment exchange phenomenon. Although sediment exchange can be represented in many ways corresponding to many different theories (e.g., diffusion, energy, mixture, similarity, and stochastic theories), distributional forms of suspended sediment concentration derived from different theories are very similar (Ni and Wand 1991).

Rouse (1937) derives a diffusion equation for suspended sediment concentration under steady state conditions based on an assumption that the logarithm law applies to distribution of flow velocity. Tsai and Tsai (2000) utilize a numerical model to obtain sediment concentration profiles and flow velocity profiles by solving a suspended sediment

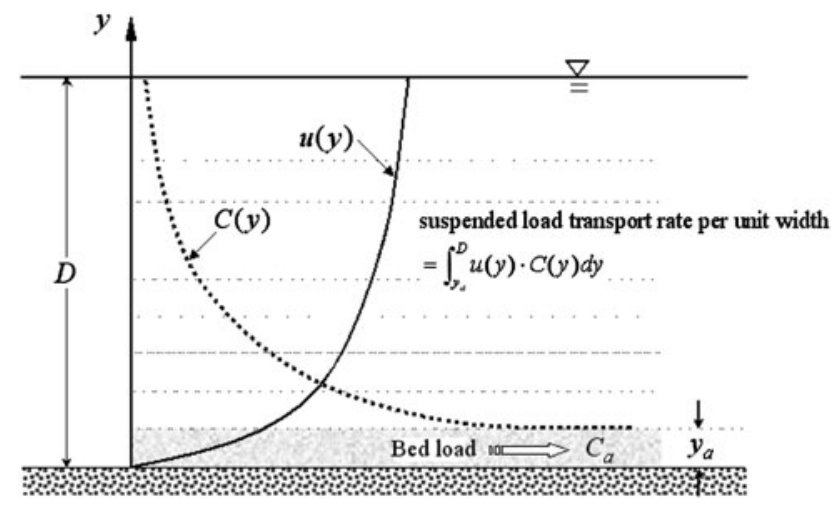

Fig. 1 Illustration of velocity and concentration profiles in open channel flow containing suspended sediment

diffusion equation and a shear equation for turbulent flow using relevant formulations for related parameters (e.g., Van Rijn's empirical formula for sediment exchange (Van Rijn 1984)). However, flow velocity and concentration at 5\% depth from bed are needed as boundary conditions for calculating concentration and velocity profiles. Therefore, the applicability of this methodology is limited.

This study modifies the methodology of Tsai and Tsai (2000) by replacing the boundary conditions with average suspended sediment concentration and average velocity. This modified methodology calculates both concentration and velocity profiles, along with the suspended sediment transport rate. Then, the bed load transport rate is calculated by concentration and flow velocity of the bed layer which are obtained from the previous steps.

Governing velocity profile equation

In an open channel, shear stress of two-dimensional turbulent flow is:

$\tau=\mu \frac{\partial u}{\partial y}-\rho \overline{u^{\prime} v^{\prime}}$

where $\tau$ is shear stress, $\mu$ is dynamic viscosity, $u$ is average flow velocity over time, $\overline{u^{\prime}}$, and $\overline{v^{\prime}}$ are average fluctuation velocity in horizontal and vertical direction, respectively; superscript "-" represents average value over time. According to Prandtl's mixing length theory, the following equation describes shear stress of flow including suspended sediment.

$\tau=\mu_{\mathrm{c}} \frac{\partial u}{\partial y}+\rho_{\mathrm{c}} \ell^{2}\left(\frac{\partial u}{\partial y}\right)^{2}$

where $\ell$ is mixing length, $\rho_{\mathrm{c}}$ and $\mu_{\mathrm{c}}$ are density and viscosity of flow containing suspended sediment, respectively. $\mu_{\mathrm{c}}$ is defined as a function of suspended sediment concentration as shown in Eq. 3 (Graf 1971): 
$\mu_{\mathrm{c}}=\mu_{\mathrm{w}}\left(1+k_{\mathrm{e}} C+k_{\mathrm{e}}^{2} C^{2}+k_{\mathrm{e}}^{3} C^{3}+\ldots\right)=\mu_{\mathrm{w}} \sum_{j=0}^{\infty}\left(k_{\mathrm{e}} C\right)^{j}$

where $\mu_{\mathrm{w}}$ is viscosity of clear water, $k_{\mathrm{e}}$ is Einstein's viscosity constant (approximated to 2.5), and $C$ is volumetric concentration of suspended sediment. $\rho_{\mathrm{c}}$ is written as:

$\rho_{\mathrm{c}}=\rho_{\mathrm{w}}(1-C)+\rho_{\mathrm{s}} C=\rho_{\mathrm{w}}+\left(\rho_{\mathrm{s}}-\rho_{\mathrm{w}}\right) C$

where $\rho_{\mathrm{w}}$ and $\rho_{\mathrm{s}}$ are the density of clear water and suspended sediment, respectively. The mixing length is assumed to be a function of volumetric concentration of suspended sediment and can be represented by Eqs. 5 and 6 (Tsai and Tsai 2000; Umeyama and Gerritsen 1992).

$\ell=\kappa y\left(1-\frac{y}{D}\right)^{\alpha}$

$\alpha=\frac{1}{2}\left(1+\beta \frac{C}{\bar{C}}\right)$

Substituting Eq. 6 into Eq. 5,

$\ell=\kappa y\left(1-\frac{y}{D}\right)^{\frac{1}{2}\left(1+\beta \frac{\underline{c}}{\bar{c}}\right)}$

where $\kappa$ is von Karman coefficient (assumed 0.4), D is depth, $\beta$ is turbulent Schmidt number which represents the relationship between suspended sediment and the mixing length, and $\bar{C}$ is the average volumetric concentration of suspended load which can be represented by Eq. 8:

$\bar{C}=\frac{\int_{y_{\mathrm{a}}}^{D} C u \mathrm{~d} y}{\int_{y_{\mathrm{a}}}^{D} u \mathrm{~d} y}$

Two-dimensional shear stress of open channel flow containing suspended sediment can be represented by Eq. 9 (Yalin 1972):

$\tau=\left(\rho_{\mathrm{c}}\right)_{m} g S D\left(1-\frac{y}{D}\right)=\left(\rho_{\mathrm{c}}\right)_{m} u_{*}^{2}\left(1-\frac{y}{D}\right)$

where $g$ is the acceleration due to gravity, $S$ is the friction slope, $u_{*}=\sqrt{g D S}$ is the shear velocity, and $\left(\rho_{\mathrm{c}}\right)_{m}$ is the density of flow containing suspended sediment from elevation, $y$ (above the bed), to the water surface:

$\left(\rho_{\mathrm{c}}\right)_{m}=\frac{1}{D-y} \int_{y}^{D} \rho_{\mathrm{c}} \mathrm{d} y$

From Eqs. 2 and 9, Eq. 11 is obtained.

$\mu_{\mathrm{c}} \frac{\partial u}{\partial y}+\rho_{\mathrm{c}} \ell^{2}\left(\frac{\partial u}{\partial y}\right)^{2}=\left(\rho_{\mathrm{c}}\right)_{m} u_{*}^{2}\left(1-\frac{y}{D}\right)$

Substitute Eqs. 3, 4, and 7 into Eq. 11, then Eq. 12 is obtained.

$$
\begin{aligned}
& \left\{\mu_{\mathrm{w}} \sum_{j=0}^{\infty}\left(k_{\mathrm{e}} C\right)^{j}+\left[\rho_{\mathrm{w}}+\left(\rho_{\mathrm{s}}-\rho_{\mathrm{w}}\right) C\right] \cdot \kappa^{2} y^{2}\left(1-\frac{y}{D}\right)^{1+\beta \frac{\bar{c}}{\bar{c}} \partial u} \frac{\partial u}{\partial y}\right\} \frac{\partial u}{\partial y} \\
& =\rho_{\mathrm{w}} u_{*}^{2}\left(1-\frac{y}{D}\right)+\left(\rho_{\mathrm{s}}-\rho_{\mathrm{w}}\right) \cdot u_{*}^{2} \frac{1}{D} \int_{y}^{D} C \mathrm{~d} y
\end{aligned}
$$

Equation 12 is the governing equation for the velocity profile of sediment-laden flow.

Governing concentration profile equation

According to diffusion theory, the concentration distribution of steady state uniform flow in an open channel is:

$w_{\mathrm{s}} C+\varepsilon_{\mathrm{s}} \frac{\partial C}{\partial y}=0$

where $\varepsilon_{\mathrm{S}}$ is the sediment momentum diffusion coefficient, and $w_{\mathrm{s}}$ is the particle fall velocity in sediment-laden flow. For flows with concentrations higher than $400 \mathrm{~kg} / \mathrm{m}^{3}$, the concentration distribution can be described as follows:

$\varepsilon_{\mathrm{s}} \frac{\partial C}{\partial y}+(1-C) \cdot C w_{\mathrm{s}}=0$

The relationship between the momentum diffusion coefficient of sediment particles and the momentum diffusion coefficient of turbulent flow is linear:

$\varepsilon_{\mathrm{s}}=\beta^{\prime} \varepsilon_{m}=\beta^{\prime} \ell^{2} \frac{\partial u}{\partial y}$

where $\beta^{\prime}$ is a constant. From the research of Coleman (1970) and Van Rijn (1984), $\beta^{\prime}$ can be expressed as:

$\beta^{\prime}=1+2\left(\frac{w_{0}}{u_{*}}\right)^{2} ; \quad 0.1<\frac{w_{0}}{u_{*}}<1.0$

where $w_{0}$ is particle fall velocity in clear water flow. $w_{0}$ can be evaluated by Chang's Formulas as (Tsai and Tsai 2000):

$w_{0}=\frac{1}{25.6}\left(S_{\mathrm{G}}-1\right) \cdot g \frac{d_{\mathrm{s}}^{2}}{v} ; \quad d_{\mathrm{s}}<0.1 \mathrm{~mm}$

$w_{0}=\sqrt{\left(13.95 \frac{v}{d_{\mathrm{s}}}\right)^{2}+1.09\left(S_{\mathrm{G}}-1\right) \cdot g d_{\mathrm{s}}}-13.95 \frac{v}{d_{\mathrm{s}}} ;$

$0.1 \mathrm{~mm}<d_{\mathrm{s}}<4 \mathrm{~mm}$

$w_{0}=1.044 \sqrt{\left(S_{\mathrm{G}}-1\right) \cdot g d_{\mathrm{s}}} ; \quad d_{\mathrm{s}}>4 \mathrm{~mm}$

where $S_{\mathrm{G}}$ is specific gravity, $v$ is the viscosity of clear water, $d_{\mathrm{s}}$ is the diameter of sediment particles. In water containing many suspended sediment particles, the velocity of sedimentation of each particle is affected by the other particles. Chien and Wan (1983) described the reduction as the following type equation:

$\frac{w_{s}}{w_{\circ}}=(1-C)^{\hat{m}}$ 
Table 1 Relationship between $\widehat{m}$ and $\left(w_{0} D / v\right)$

\begin{tabular}{|c|c|c|c|c|c|c|c|c|c|c|c|c|}
\hline$\frac{w_{0} D}{v}$ & $\leqq 0.1$ & 0.2 & 0.5 & 1 & 2 & 5 & 10 & 20 & 50 & 100 & 200 & $\geqq 500$ \\
\hline$\widehat{m}$ & 4.91 & 4.89 & 4.83 & 4.78 & 4.69 & 4.51 & 4.25 & 3.89 & 3.33 & 2.92 & 2.58 & 2.25 \\
\hline
\end{tabular}

where, $\hat{m}$ is an unknown parameter and is a function of Reynolds number (Table 1) (Tsai and Tsai 2000). Therefore, Eq. 14 can be written as follows:

$$
\begin{aligned}
& {\left[1+2\left(\frac{w_{0}}{u_{*}}\right)^{2}\right] \kappa^{2} y^{2}\left(1-\frac{y}{D}\right)^{1+\beta \frac{\bar{c}}{\bar{c}} \frac{\partial u \partial C}{\partial y \partial y}}} \\
& +w_{0} C(1-C)^{\widehat{m}+1}=0
\end{aligned}
$$

Equation 21 is the governing equation for concentration profiles of water containing suspended sediment.

From Eqs. 12 and 21, suspended load transport rate, bed load transport rate and both the velocity and concentration profiles of water containing suspended sediment are obtained.

\section{Boundary conditions}

Boundary conditions consisting of flow velocity, $U_{\mathrm{a}}$, and suspended sediment concentration, $C_{\mathrm{a}}$, at the surface of the bed layer, are needed to solve Eqs. 12 and 21. The flow velocity at the surface of the bed layer can be described as follows:

$U_{\mathrm{a}}=u_{*} \cdot 5.75 \log _{10}\left(\frac{30.2 y_{\mathrm{a}} \chi}{k_{\mathrm{s}}}\right)$

where $k_{\mathrm{s}}$ is the bed roughness and $\chi$ is the adjustment coefficient. The bed roughness is suggested as $d_{65}$ by EinsteinBarbarossa (Yang 1996). However, this study uses $d_{50}$ because only $d_{50}$ data are available. The adjustment coefficient, a function of $k_{\mathrm{S}} / \delta$, represents the characteristics of the transformation from a smooth bed to a rough bed and can be obtained from Fig. 2. The denominator, $\delta$, is the thickness of viscous sublayer and can be described as follows:

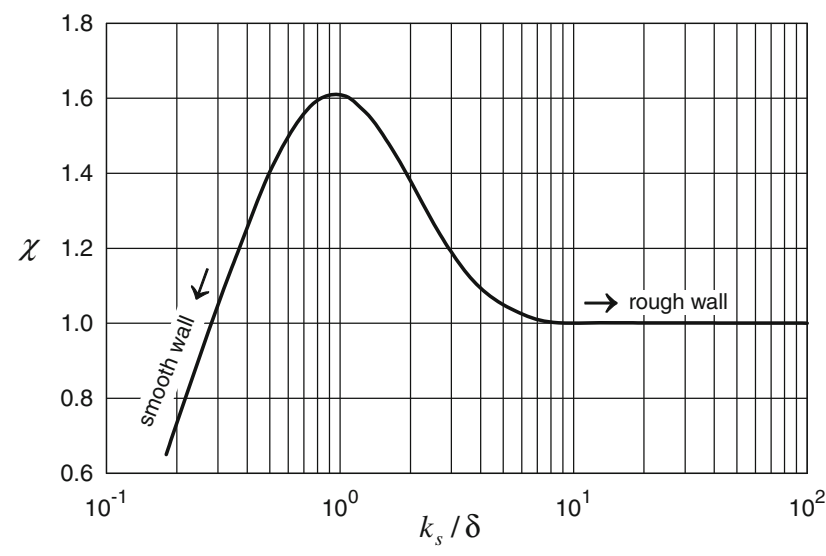

Fig. 2 Correctness coefficient curve (Einstein 1950) $\delta=\frac{11.6 v}{u_{*}^{\prime}}$

where $u_{*}^{\prime}$ is the shear velocity of particle roughness.

Concentration of suspended load at the surface of the bed layer is rarely observed. Instead, an average concentration is measured. Therefore, this paper applies known average velocity and concentration to determine $C_{\mathrm{a}}$ by a trial-and-error method. Since the turbulent Schmidt number, $\beta$, affects the distribution of flow velocity and concentration, a proper $\beta$ value is also needed. Umeyama and Gerritsen (1992) suggested that $\beta$ can be calculated using Prandtl's mixing length theory and measured mixing length data. However, the mixing length in open channel flow containing suspended sediment is very difficult to obtain. Tsai and Tsai (2000) suggested that $\beta$ be estimated by regression analysis of the relationship between $\beta$ and $C_{\mathrm{a}}$.

This paper assumes an initial value of zero for $\beta$. The value of $\beta$ is automatically updated by the model according to the calculated and measured average flow velocity and concentration.

\section{Bed-material load model}

The flow velocity profile and suspended sediment concentration profile between the water surface and bed layer surface can be obtained by solving Eqs. 12 and 21. The integrated product of these two profiles is the suspended load transport rate. Because the bed layer is very thin, the concentration in the bed layer is considered constant, which means that the concentrations at the bed surface and at the bed layer surface are the same. Therefore, bed load transport rate can be calculated using concentration and flow velocity at the surface of bed layer. The summation of calculated suspended load transport rate and bed load transport rate is the bed-material transport rate.

Equation 13 is the diffusion equation for steady state. However, if the flush load is not saturated with suspended sediment, Eq. 13 is not applicable. Both suspended load transport rate and bed load transport rate obtained from Eq. 13 belong to bed-material load. Therefore, the summation of these two rates is the bed-material transport rate.

\section{Numerical model}

This study uses numerical techniques to solve the governing equations of flow velocity and suspended sediment 
concentration profiles. The numerical model discretizes the distance between the water surface and bed layer surface by $N$ nodes and solves the equations by forward finite difference method. The discretization of differential terms of Eqs. 12 and 21 are:

$$
\begin{aligned}
& \frac{\partial u}{\partial y}=\frac{u_{i+1}-u_{i}}{y_{i+1}-y_{i}} \\
& \frac{\partial C}{\partial y}=\frac{C_{i+1}-C_{i}}{y_{i+1}-y_{i}}
\end{aligned}
$$

where $i=1, \ldots, N-1$. Iterations are needed to solve these equations because both of the governing equations are nonlinear partial differential equations. The differential equations for Eq. 12 can be approximated as:

$$
\begin{aligned}
& u_{i+1}^{k+1}=u_{i}^{k+1}+\frac{1}{A_{\mathrm{u}}}\left[\rho_{\mathrm{w}} u_{*}^{2}\left(1-\frac{y_{\mathrm{ave}}}{D}\right)+B_{\mathrm{u}}\right] \\
& A_{\mathrm{u}}=\frac{\mu_{c}^{k}}{\left(y_{i+1}-y_{i}\right)}+\frac{\rho_{\mathrm{c}}^{k}\left(\ell^{k}\right)^{2}\left(u_{i+1}^{k}-u_{i}^{k}\right)}{\left(y_{i+1}-y_{i}\right)^{2}} \\
& B_{\mathrm{u}}=\left(\rho_{\mathrm{s}}-\rho_{\mathrm{w}}\right) u_{*}^{k} \frac{1}{D} \int_{y}^{D} C^{k} \mathrm{~d} y \\
& =\left(\rho_{\mathrm{s}}-\rho_{\mathrm{w}}\right) u_{*}^{k} \frac{1}{D}\left(\sum_{i=1}^{N} C_{i}^{k} \Delta y_{i}\right) \\
& \mu_{\mathrm{c}}^{k}=\mu_{\mathrm{w}} \sum_{j=0}^{\infty}\left(k_{\mathrm{e}} C_{\mathrm{ave}}^{k}\right)^{j} \\
& \rho_{\mathrm{c}}^{k}=\left[\rho_{\mathrm{w}}+\left(\rho_{\mathrm{s}}-\rho_{\mathrm{w}}\right) C_{\mathrm{ave}}^{k}\right] \\
& \left(\ell^{k}\right)^{2}=\kappa^{2} y_{\mathrm{ave}}^{2}\left(1-\frac{y_{\mathrm{ave}}}{D}\right)^{1+\beta \frac{\mathrm{arve}^{k}}{C^{k}}}
\end{aligned}
$$

where subscript "ave" represents average value of grid $i$ and $i+1$, and superscript $k$ represents the value of previous iteration. Likewise, Eq. 21 can be approximated as:

$C_{i+1}^{k+1}=\frac{C_{i}^{k+1}}{A_{\mathrm{c}}}\left[A_{\mathrm{c}}-w_{\mathrm{o}}\left(1-C_{\mathrm{ave}}^{k}\right)^{\widehat{m}+1}\right]$

$A_{\mathrm{c}}=\frac{\varepsilon_{\mathrm{s}}^{k}}{y_{i+1}-y_{i}}+\frac{w_{\circ}}{2}\left(1-C_{\mathrm{ave}}^{k}\right)^{\widehat{m}+1}$

$\varepsilon_{\mathrm{s}}^{k}=\left[1+2\left(\frac{w_{\circ}}{u_{*}}\right)^{2}\right] \kappa^{2} y_{\mathrm{ave}}^{2}\left(1-\frac{y_{\mathrm{ave}}}{D}\right)^{1+\beta \frac{C_{\mathrm{ave}}^{k}}{c^{k}}}\left(\frac{u_{i+1}^{k}-u_{i}^{k}}{y_{i+1}-y_{i}}\right)$

Equations 32, 33, and 34 are differential equations for calculating concentration profile $C$. Based on the velocity profile and concentration profile obtained from above equations, suspended load transport rate can be calculated by Eq. 35 .
Input data and data preparation

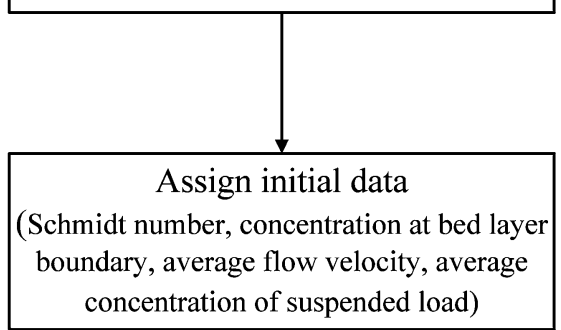

Calculate flow velocity at bed layer boundary

(Using equation (22))



Fig. 3 Flow chart for numerical procedure 
Fig. 4 Case selection of flow containing suspended sediment based on Shields parameterlaboratory data

Fig. 5 Case selection of flow containing suspended sediment based on Shields parameter Field data
Laboratory data

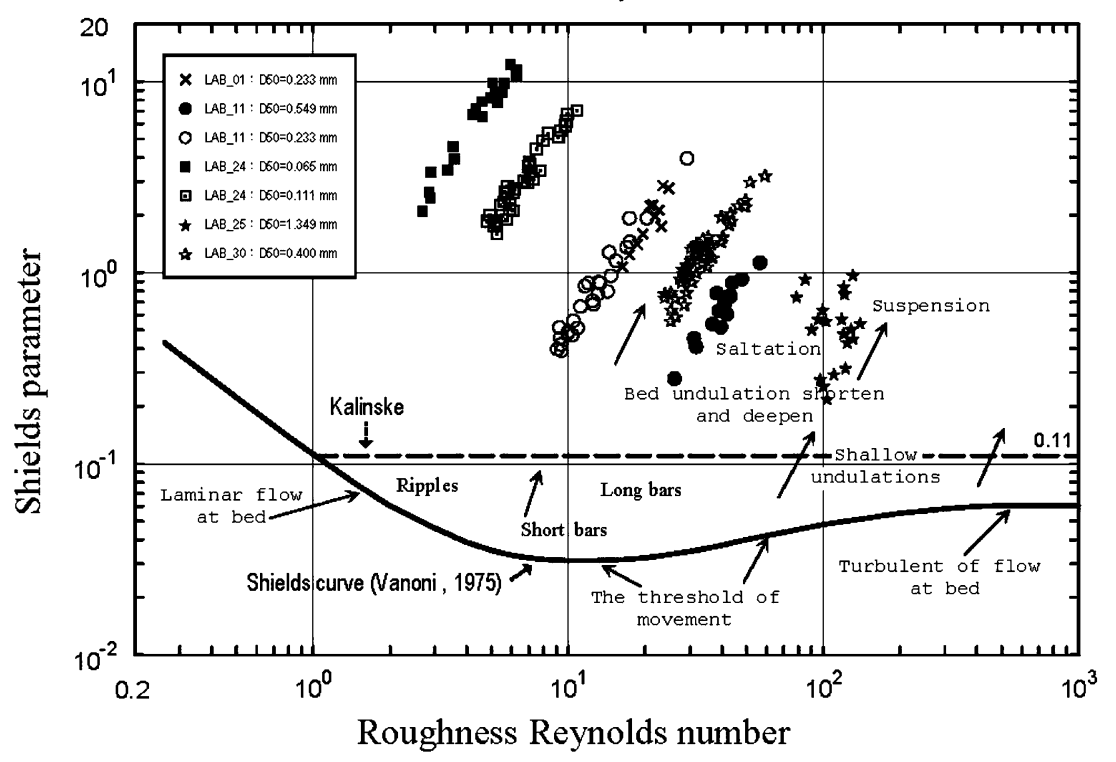

Field data

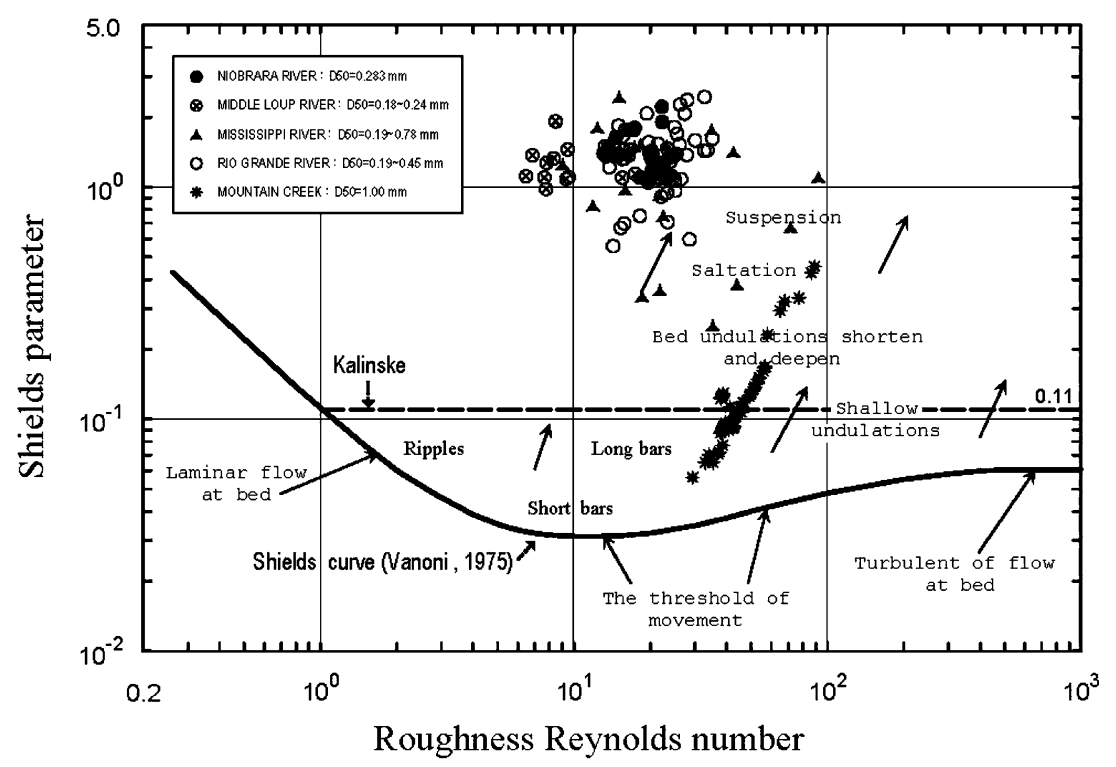

defined the thickness by the distance between the bed surface and the top of the saltation layer. Zyserman and Fredsoe (1994) suggested that bed layer thickness should be defined as a multiple of particle diameter. Nino and Garcia (1998) suggested that the thickness of the saltation layer be between 1.3 and 1.8 times the particle diameter based on lab experiments. Wilson (1988) stated that the bed roughness affects the thickness and suggested that the thickness be defined as $10 \theta d$, where $\theta\left(=u_{*}^{2} / g d s\right)$ is the Shields parameter, $d$ is the particle diameter of the bedmaterial, and $s=\left(\rho_{\mathrm{s}} / \rho-1\right)$.

To account for different types of channel beds in rivers, Van Rijn (1984) suggested using half of the bed-wave 
Table 2 Sediment transportation data from the U.S. Bureau of Reclamation

\begin{tabular}{clrl}
\hline Number & Name & Year & $\begin{array}{l}\text { No. of } \\
\text { data }\end{array}$ \\
\hline $\begin{array}{c}\text { Lab data } \\
\text { Lab_01 }\end{array}$ & Ansley, Ralph William & 1963 & $13(13)$ \\
Lab_11-1 & Kennedy, J.F. & 1961 & $12(3)$ \\
Lab_11-2 & Kennedy, J.F. & 1961 & $16(9)$ \\
Lab_24-1 & Wang, S. Chen, J., and Hui, Y & 1998 & $21(21)$ \\
Lab_24-2 & Wang, S. Chen, J., and Hui, Y & 1998 & $35(35)$ \\
Lab_25 & William, G.P. & 1970 & $20(3)$ \\
Lab_30 & Stein, R.A. & 1965 & $52(43)$ \\
Field data & & & \\
River_01 & Niobrara river near Cody, Nebraska & 1955 & $25(25)$ \\
River_02 & Middle Loup river at Dunning, Nebraska & 1959 & $15(15)$ \\
River_03 & Mississippi river at ST. Louis, Missouri & 1965 & $23(18)$ \\
River_04 & Rio Grande river, New Mexico & 1964 & $42(36)$ \\
River_05 & Mountain Creek & 1944 & $61(0)$ \\
\hline
\end{tabular}

Note: The number in parentheses in the No. of data column shows the number of data selected based on Shields parameter (Fig. 6a, b). In this study, cases with 0.8 or larger values of Shields parameter are selected

height for equivalent roughness height. Cao (1999) suggested that the thickness should not be less than $1 \%$ of the flow depth. Gracia and Parker (1991) suggested that the thickness be defined as $5 \%$ of the water depth.

In this study, a uniform distribution of sediment concentration is assumed. Therefore, the bed load transport rate per unit width can be represented by the following:

$q_{\mathrm{b}}=\alpha \cdot \rho_{\mathrm{s}} \cdot U_{\mathrm{a}} \cdot C_{\mathrm{a}} \cdot y_{\mathrm{a}}$

where, $q_{\mathrm{b}}$ is the bed load transport rate per unit width $(\mathrm{kg} /$ $\mathrm{s} \mathrm{m})$; and $\alpha$ is a correctness coefficient. When bed load concentration is uniformly distributed, the coefficient $\alpha$ equals 1 .

Equations 35 and 36 calculate suspended load transport rate and bed load transport rate. The bed-material transport rate, $q_{\mathrm{bm}}$, is defined as the sum of these two rates.

$q_{\mathrm{bm}}=q_{\mathrm{b}}+q_{\mathrm{s}}$

Calculation procedures

The following shows the procedures for estimating bed load transport by this numerical method as well as by a tryand-error method. A flow chart is shown in Fig. 3.

(1) Known: geometric shape of river channel, roughness slope $(S)$, average flow depth $(D)$, sediment density $\left(\rho_{\mathrm{s}}\right)$, water density $\left(\rho_{\mathrm{w}}\right)$, von Kármán coefficient $(\kappa)$, water dynamic viscosity $\left(\mu_{\mathrm{w}}\right)$, particle diameter of bed-material $\left(d_{\mathrm{s}}\right)$, average flow velocity $(\bar{u})$, and average concentration of suspended load $(\bar{C})$.

(2) Assign a value of turbulent Schmidt number $(\beta)$. (Initial guess of $\beta$ is zero.)

(3) Calculate flow velocity at bed layer boundary $\left(U_{\mathrm{a}}\right)$ using Eq. 22.

(4) Assign a concentration at bed layer boundary. (Initial guess of $C_{\mathrm{a}}$ is $10 \times \bar{C}$ )

(5) Assign initial $u_{i}\left(u_{i}=\bar{u}\right)$ and initial $C_{i}\left(C_{i}=1 \times\right.$ $10^{-5}$.

(6) Calculate profile of flow velocity $\left(u_{i+1}\right)$ and suspended load concentration $\left(C_{i+1}\right)$ for $i=1, \ldots$, $N-1$ using Eqs. 26 and 32 with the try-and-error method.

(7) Calculate average concentration $(\bar{C})$ and average flow velocity $(\bar{u})$ using results obtained from step (6).

(8) Compare calculated average concentration $\left(\bar{C}^{*}\right)$ and measured average concentration $(\bar{C})$. If the error is larger than the tolerance, a relative error criterion $\left(\left|\frac{\bar{C}^{*}-\bar{C}}{\bar{C}}\right| \leq 10^{-4}\right)$, repeat step (6) until the result is satisfactory.

(9) Calculate suspended load transport rate using Eq. 35.

(10) Calculate bed load transport rate using Eq. 37.

\section{Model application and discussion}

Large amounts of data related to sediment transport in channels from both experiments in the laboratory and measurements in real-world rivers, were obtained from the U.S. Bureau of Reclamation (USBR). Sediment transport data was obtained at five rivers: Mississippi River, Niobrara River, Rio Grande, Middle Loup River, and Mountain Creek. However, these data are concentrations of bed-material load in ppm by weight and cannot be used to distinguish between bed-material and suspended-material. In this study, the bedmaterial load model is used to estimate bed-material load transport using laboratory data and the measurements obtained from the five rivers. The results are compared with those obtained using the Einstein bed load function.

This study selects cases using Shields parameter (or entrainment function) and applies the proposed methodology to these selected cases to calculate the suspendedmaterial and bed-material load.

In this study, water flow is considered to contain suspended load if the Shields parameter of the experiment or river is larger than 0.8. Figures 4 and 5 show the results of case selection based on the Shield parameter. Tables 2, 3, and 4 show the number and content (including the range of the Shields parameter) of these data. One hundred twenty- 


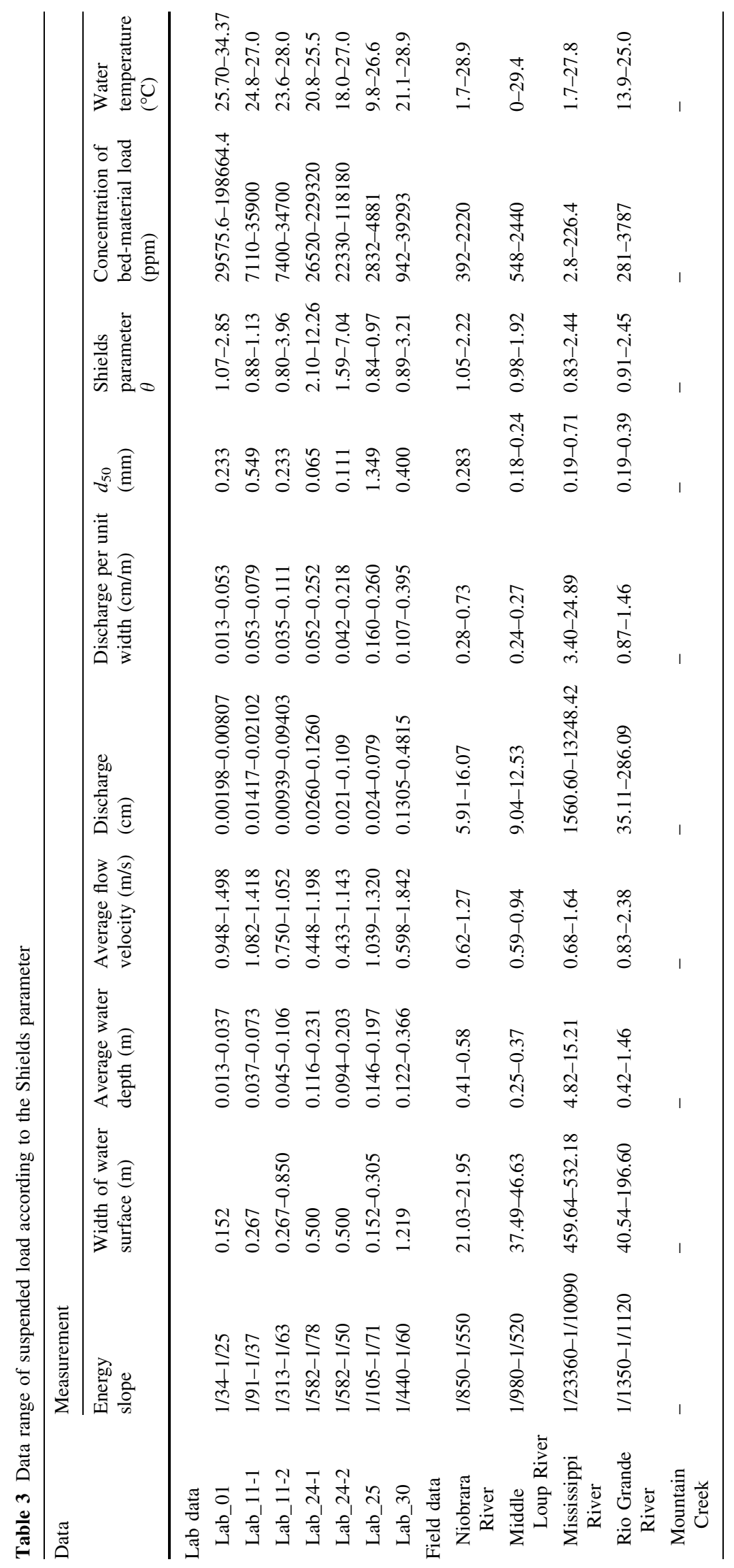




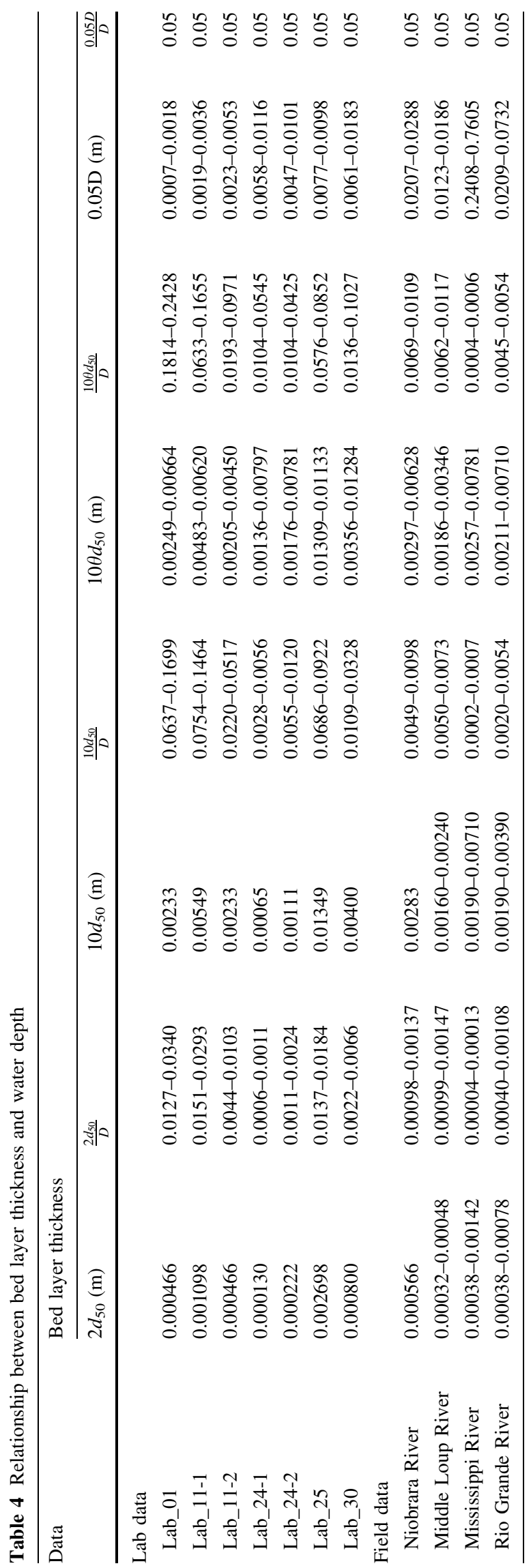



Fig. 6 Comparison of four definitions of bed layer thickness

seven data sets from laboratory experiments and 94 data sets from river measurements are classified as water containing suspended load. Note that the results indicate that there is no suspended load in Mountain Creek (based on river data).

The effect associated with bed-material thickness

Table 4 shows the relationship between bed layer thickness and water depth based on four definitions of bed layer thickness. Field measurement data show that the thickness defined by $0.05 D$ results in a thicker bed layer. In contrast to measurement data, lab experiment data show that the thickness defined by $2 d$ results in a thinner bed layer and the ratio of bed layer thickness to flow depth is always smaller than 0.05. However, the cases of $10 d$ and $10 \theta d$ show the variety of the ratio values. Figure 6 shows the comparison of these two cases with a bed layer thickness of $0.05 D$. The result shows that the two cases have a greater layer thickness than the case of $0.05 D$.

Figures 7 and 8 show a comparison between the modelcalculated results based on a laboratory experiment (Lab_01) and those of field measurements (Rio Grande River). Figure 7 shows the concentration profiles of suspended load and velocity for four different definitions of the bed layer thickness. Figure 8 shows the profile of suspended load which is product of velocity and concentration. The comparison indicates that the results are generally similar except for two special cases: a thickness of $0.05 D$ for field measured data, and a thickness of $10 \theta d$ for laboratory data have relatively high suspended load. A conjecture of this high load is that the thicknesses of these two cases are larger than the others. Larger thickness means shallow depth which leads to higher concentration and higher velocity. 

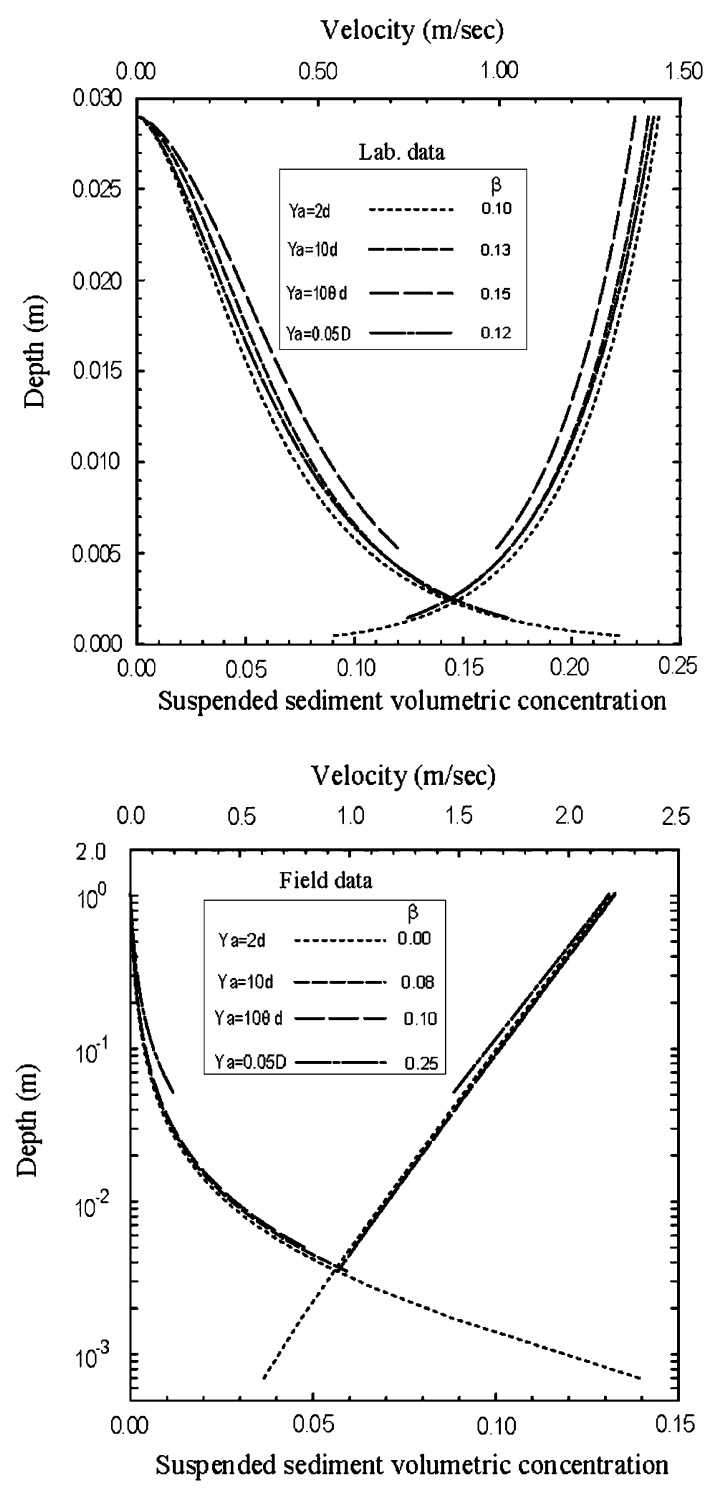

Fig. 7 Calculated profiles of flow velocity and concentration

The viscosity of flow containing suspended sediment

To determine the power term, $j$, in Eq. 3, the effects of this parameter must be evaluated. Figures 9 and 10 show the comparison between the results of higher concentration cases of the laboratory experiment and field measurements. This comparison indicates that the cases where $j=3$ and $j>3$ arrive at the same result. Therefore, the power term $j$ is defined as 3 in this study.

Results and discussion of the laboratory experiment cases

In this paper, bed load transport rate and suspended load transport rate of selected cases were analyzed using the proposed numerical model. This analysis utilized
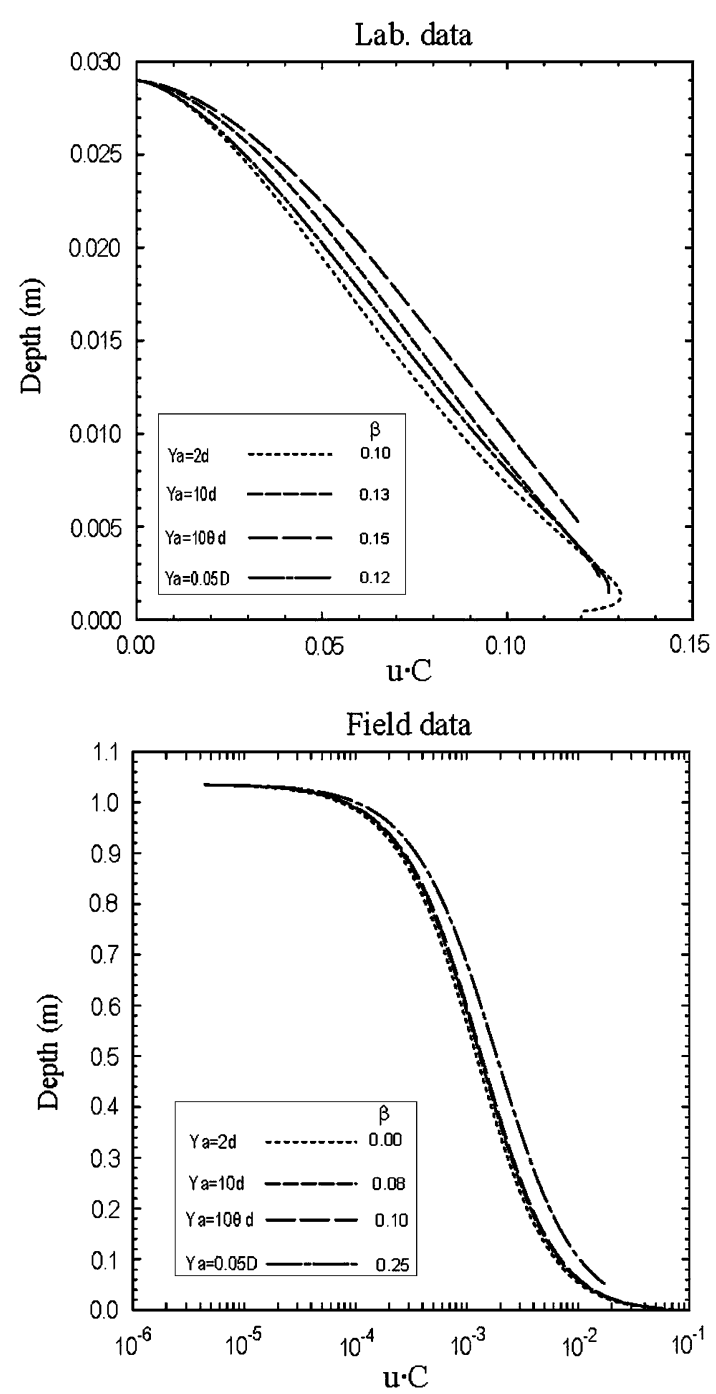

Fig. 8 Product of flow velocity and concentration for cases with different water depths

suspended load from laboratory data based on the Shields parameter and Reynolds number (Tables 2, 3; Fig. 3). Four kinds of layer thicknesses $(2 d, 10 d, 10 \theta d$, and $0.05 D)$ are used to calculate profiles of both flow velocity and suspended concentration along with bed load transport rate. Figure 11 shows a comparison between the proposed model-calculated results and those using Einstein's bed load function.

In Fig. 11, the $X$ and $Y$ coordinates are flow strength factor, $\Psi_{*}$, and bed load transport factor, $\Phi_{*}$, defined as follows:

$\Psi_{*}=\xi Y\left(\frac{\hat{\beta}}{\beta_{x}}\right)^{2} \frac{\gamma_{\mathrm{s}}-\gamma d}{\gamma R^{\prime} S}$

$\Phi_{*}=\frac{q_{\mathrm{b}}}{\gamma_{\mathrm{s}}} \sqrt{\frac{\rho}{\rho_{\mathrm{s}}-\rho g d^{3}}}$ 

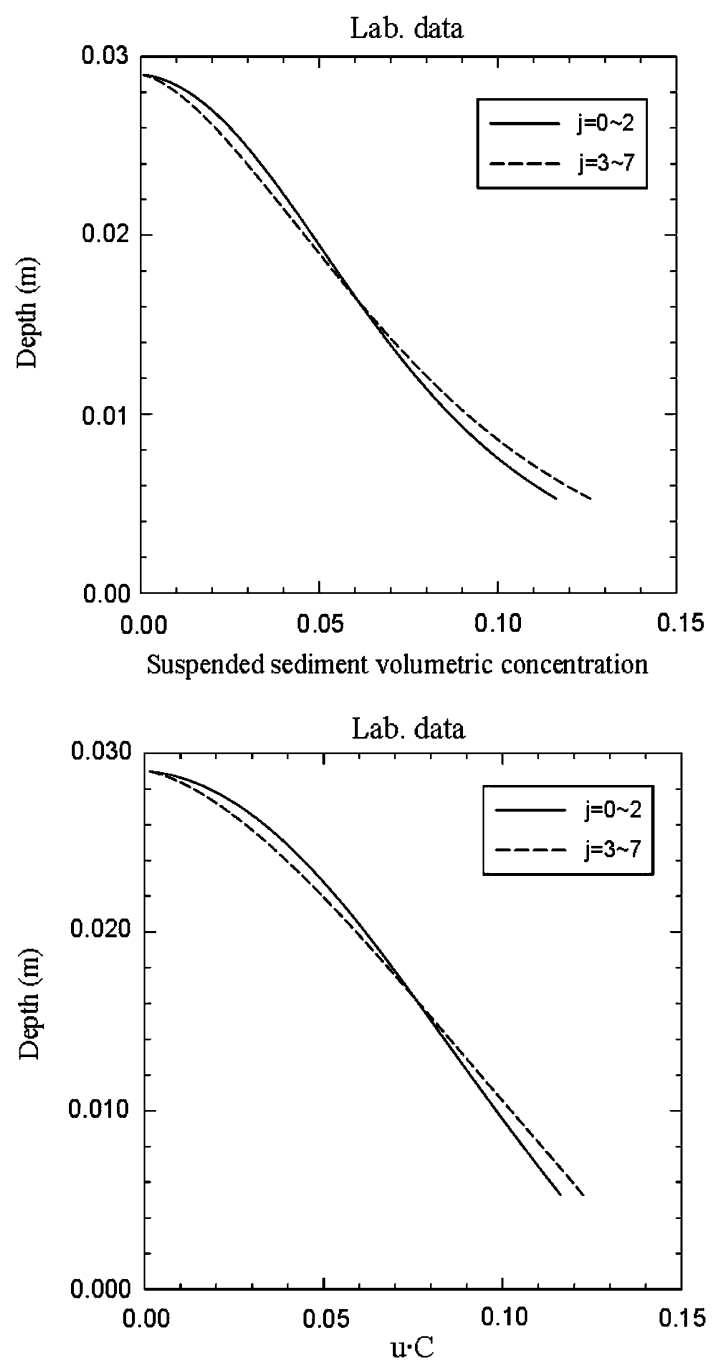

Fig. 9 Relationship between model-calculated results and the power term, $j$, in Eq. 3 -laboratory data

where $\gamma$ and $\gamma_{\mathrm{s}}$ are the unit weights of water and sediment, respectively; $\xi$ is a hiding factor; $Y$ is the correctness coefficient of lift force; $\beta_{x}=\log _{10}(10.6 X / \Delta) ; \mathrm{X}$ is the characteristic distance $(X=0.77$ while $\Delta / \delta>1.8$ and $X=1.39$ while $\Delta / \delta<1.8) ; \Delta=k_{\mathrm{s}} / \chi$ is the apparent roughness diameter for bed surface; $\chi$ is the correctness coefficient of logarithmic flow velocity for the transition from smooth to rough bed surface (can be obtained by Fig. 2); $\hat{\beta}=\log _{10}(10.6)$; and $R^{\prime}$ is the hydraulic radius of particle roughness which is obtained using the Einstein function. We assume a value of one for $\xi, Y$, and $\left(\hat{\beta} / \beta_{x}\right)^{2}$ because of the lack of these data.

In the cases where thickness is defined as $10 \theta d$ and $0.05 \mathrm{D}$, the model-calculated results are very close to those of the Einstein's bed load function (Einstein 1950). For the $10 d$ and $2 d$ cases, the model-calculated results show
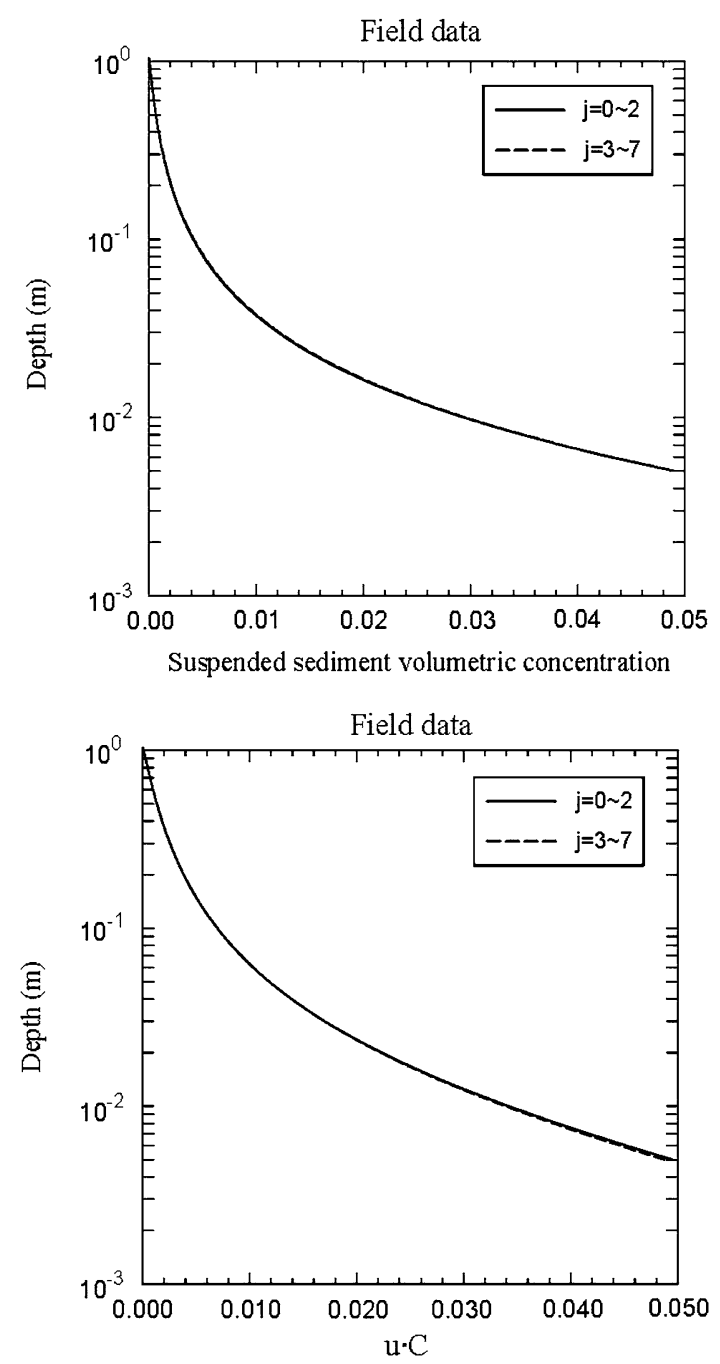

Fig. 10 Relationship between model-calculated results and the power term, $j$, in Eq. 3-field data

smaller values of the flow strength factor, under the same bed load transport factor, than Einstein's bed load function.

Results and discussion of the field measurement cases

The cases analyzed were selected based on the Shields parameter and the Reynolds number (Tables 2, 3; Fig. 4). The comparison between the model-calculated bed load transport rate and that of Einstein's bed load function is shown in Fig. 12. This comparison shows that the proposed model obtains similar results to the Einstein's bed load function in the case of $0.05 \mathrm{D}$ and, however, smaller values than those obtained using Einstein's function in the cases of $2 d, 10 d$, and $10 \theta d$. Moreover, the proposed model obtained similar results in the cases of $10 d$, and $10 \theta d$.

In summary, the bed load transport rate is underestimated in the case of $2 d$, both in the laboratory experiment 
Fig. 11 Comparison between model-calculated results and those of Einstein's bed load function-laboratory data
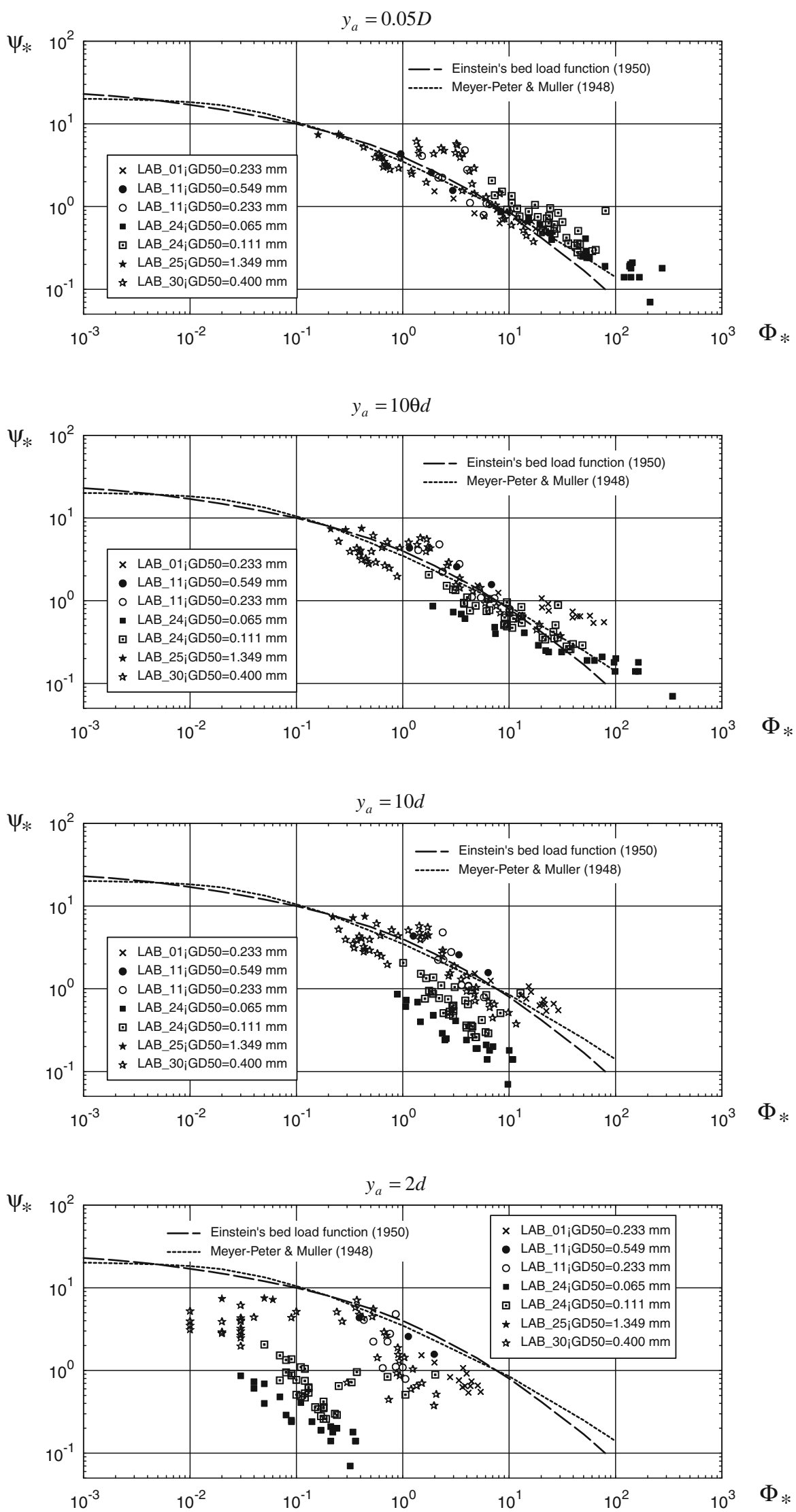
Fig. 12 Comparison between model-calculated results and those of Einstein's bed load function-field data
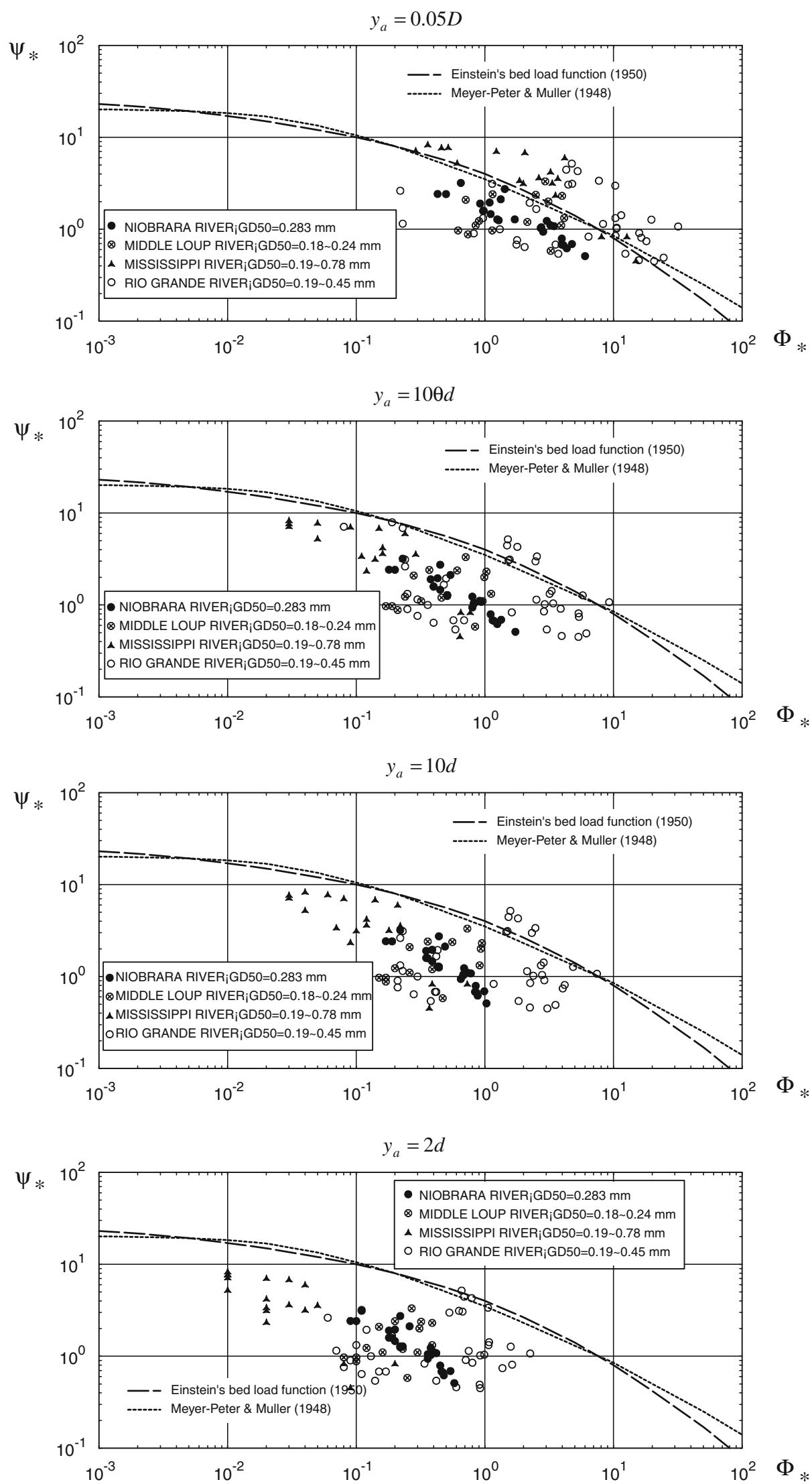
and field measurement. Therefore, a bed layer thickness of $10 \theta d$ or $0.05 D$ for laboratory experiment cases and $0.05 \mathrm{D}$ for field measurement cases is suggested.

In addition, based on Fig. 8, thinner bed layer leads to a lower product of suspended concentration and flow velocity; however, a thinner layer results in a deeper flow depth thus a higher production value occurs at the area where near bed layer. Therefore, a thinner bed layer leads to a higher suspended load transport rate and a lower bed load transport rate. This result can be also seen in Fig. 11.

\section{Conclusion}

A bed-material load model was developed by solving shear stress equation of two-dimensional turbulent flow and concentration distribution equation of sediment-laden flow. The proposed model can obtain both velocity profiles and concentration profiles of sediment-laden flow using measured average flow velocity and average concentration of suspended sediment. Utilizing these profiles, the bed load and suspend load can be obtained. Moreover, the sediment transport calculated by the model is more reliable and more adaptive than sediment transport formulas to the plan for improving the stability of the irrigation channel. Based on the comparisons of calculated results and laboratory and field data, the other conclusions were made:

1. The thickness of the bed layer affects the distribution of flow velocity and suspended load concentration. The results of the laboratory experiment cases show that a thinner bed layer thickness leads to a larger area of suspended sediment movement and higher concentrations near the bed layer. Therefore, a thinner bed layer results in a higher suspended load transport rate and a lower bed load transport rate.

2. To calculate the viscosity of sediment-laden flow, the power term, $j$, of Eq. 3 should be assigned a value of 3 .

3. The proposed model obtains similar results to Einstein's bed load function when bed layer thickness is defined as $100 d$ or $0.05 D$ for laboratory cases. Also, the model obtains similar results to Einstein's bed load function when bed layer thickness is defined as $0.05 \mathrm{D}$ for field measurement cases.
Open Access This article is distributed under the terms of the Creative Commons Attribution Noncommercial License which permits any noncommercial use, distribution, and reproduction in any medium, provided the original author(s) and source are credited.

\section{References}

Cao Z (1999) Equilibrium near bed concentration of suspended sediment. J Hydraul Eng ASCE 125(12):1270-1278

Chien N, Wan Z (1983) Mechanics of sediment transport. Science Press, Beijing, China

Coleman NL (1970) Flume studies of the sediment transfer coefficient. Water Resour Res 3(6):801-809

Einstein HA (1950) The bed-load function for sediment transportation in open channel flow. Tech. Bull. No. 1026, U.S. Dept. of Agriculture, Washington, DC

Engelund F, Fredsoe J (1976) A sediment transport model for straight alluvial channels. Nordic Hydrol 5(7):293-306

Gracia M, Parker G (1991) Entrainment of bed sediment into suspension. J Hydraul Eng ASCE 117(4):414-435

Graf WH (1971) Hydraulics of sediment transport. McGraw-Hill Book Co., Inc., New York

Jung KT, Jin JY, Kang HW, Lee HJ (2004) An analytical solution for the local suspended sediment concentration profile in tidal sea region. Estuar Coast Shelf Sci 61(4):657-667

Lin MY, Huang LH (2008) Velocity profiles of nonlinear shallowwater flows. J Chin Inst Eng 31(1):105-120

Ni JR, Wand GQ (1991) Vertical sediment distribution. J Hydraul Eng ASCE 117(9):1184-1194

Nino Y, Garcia M (1998) Experiment on saltation of sand in water. J Hydraul Eng ASCE 124(10):1014-1025

Rouse H (1937) Modern conceptions of the mechanics of fluid turbulence. Trans ASCE 102:463-505

Smith JD, Mclean SR (1977) Spatially averaged flow over a wavy surface. J Geophys Res 82(12):1735-1746

Tsai CH, Tsai CT (2000) Velocity and concentration distributions of sediment-laden open channel flow. J Am Water Resour Assoc 36(5):1075-1086

Umeyama M, Gerritsen F (1992) Velocity distribution in uniform sediment-laden flow. J Hydraul Eng ASCE 118(2):229-245

Van Rijn LC (1984) Sediment transport, part II: suspended load transport. J Hydraul Eng ASCE 110(11):1613-1641

Wang XK, Wang ZY, Yu MZ, Li DX (2001) Velocity profile of sediment suspensions and comparison of log-law and wake-law. J Hydraul Res 39(2):211-217

Wilson KC (1988) Frictional behavior of sheet flow. Progress Rep. 67, ISVA, Technical University of Demark, Lyngby, Demark, pp 11-22

Yalin MS (1972) Mechanics of sediment transport. Pergamon Press, Inc., New York

Yang CT (1996) Sediment transport: theory and practice. The McGraw-Hill Companies, Inc., New York

Zyserman JA, Fredsoe J (1994) Data analysis of bed concentration of suspended sediment. J Hydraul Eng ASCE 120(9):1021-1042 